\title{
NITRIC OXIDE MAY REGULATE FOCAL ADHESION TURNOVER AND CELL MIGRATION IN MDA-MB-231 BREAST CANCER CELLS BY MODULATING EARLY ENDOSOME TRAFFICKING
}

\author{
Dhurgham Al-Fahad ${ }^{1}$, Bandar Fahad Alharbi², Clementino Ibeas Bih ${ }^{3}$, Philip Richard Dash ${ }^{4}$
}

\begin{abstract}
Cell migration is an essential process for wound healing, metastasis and inflammation. Focal adhesions (FA) are local regions of plasma membrane consisting of multiprotein complexes providing adhesive contact between the cell and the extracellular matrix (ECM). FA turnover regulates different signalling pathways implicated in various cellular responses (e.g. cell migration). Endocytosis, specifically the dynamin and clathrin pathways, is known to regulate cell migration by modulating FA dynamics. In this study, we investigated whether NO activity regulates cell migration, FA dynamics and early endosome trafficking in MDA-MB-231 cells. The assessment of cell migration showed a slowing down of cell migration and an increased duration of FA turnover in cells treated with inhibitors of NO synthase (NOS) such as L-NAME or $1400 \mathrm{~W}$. In addition, these treatments were found to exhibit no effect on transferrin and dextran uptake mediated by endocytosis and micropinocytosis, respectively. The number of early endosome antigen 1 (EEA1)-positive endosomes was reduced while their sizes were found to increase in cells treated with L-NAME or $1400 \mathrm{~W}$. In contrast, these inhibitors did not affect the number nor the size of Rab5-positive endosomes. Furthermore, we demonstrated that EEA1, endothelial NO synthase (eNOS) and inducible NO synthase (iNOS) were colocalised. Using the biotin switch assay followed by western blot, we showed that early endosome proteins such as APPL1, EEA1, Rab5 were found to be S-nitrosylated. These results were further supported by the sequence analysis performed with the GPS-SNO algorithm which predicted the S-nitrosylation of these endosomal proteins. Taken together, our findings suggest that NO might be involved in cell migration and FA turnover through early endosome trafficking in MDA-MB-231 cells.
\end{abstract}

Running title: Nitric oxide in MDA-MB-231 breast cancer cells

Keywords: cell migration, focal adhesion, nitric oxide, endocytosis, endosome, breast cancer

\footnotetext{
${ }^{1}$ University of Thi-Qar, Department of Pathological Analysis, College of Science, Thi-Qar, Iraq

${ }^{2}$ University of Hail, Department of clinical laboratory, College of Applied Medical Science, Hail, Saudia Arabia

${ }^{3}$ Ilumix Biotech Ltd, London, United Kingdom

${ }^{4}$ University of Reading, Department of Biomedical, School of Biological Sciences, Reading, United Kingdom

*Correspondence: b.alharbi@uoh.edu.sa

Full list of author information is available at the end of article
} 


\section{Introduction}

Nitric oxide (NO) is a colourless, highly lipophilic and diffusible gas. The molecule is made up of an oxygen atom bound to a nitrogen atom. Most mammalian tissues express different NO synthases (NOS) - a group of enzymes responsible for the synthesis of NO. Three isoforms of NOS enzymes, namely the neuronal NOS (nNOS), the inducible NOS (iNOS) and the endotheial NOS (eNOS) have been detected in a wide range of human cell lines [1]. NO plays an important role in mediating a number of biological processes, such as cell migration [2]. Three different isoforms of NOS (eNOS, nNOS and iNOS) which produce NO, have been found in a wide range of human cell lines. The expression of different NOS isoforms has been reported to increase in breast cancer as well as other cancers such as the cancer of the colon, lung cancer, lymphoma, and melanoma [1,3-6]. A number of studies have demonstrated a relationship between NO expression and cell migration. For example, in wound healing assays high levels of NO has been found to promote both wound healing as well as the proliferation of human keratinocyte cells [7]. Whereas low levels of NO is conducive to the delaying of wound healing [8].

Endocytosis mediated by caveolae play an important role in NO activity [9]. It is involved in the regulation of a range of important cellular activities such as transmembrane signalling and endocytosis. It has been shown that eNOS directly binds to caveolae and interacts with many signalling factors found within the caveolae coat [10]. A subcellular fractionation of endothelial cells revealed that eNOS was particularly present in the caveolae fraction [11]. NOS mediates S-nitrosylation of proteins which in turn can alter the structure and function of proteins and protein-protein interactions $[12,13]$. A growing body of evidence suggests that S-nitrosylation is implicated in endocytosis and cell migration [12]. GTP hydrolysis activity of dynamin proteins has been shown to increase following their S-nitrosylation - possibly mediated by eNOS [12,14]. This results in the increase of dynamin GTP hydrolysis activity, which has been shown to accelerate the endocytosis of plasma membrane receptor by enhancing the cleavage of vesicles [12]. Aside from endocytosis, the S-nitrosylation of protein has been implicated in (focal adhesion) FA disassembly in a process that requires the calcium-dependent protease calpain. Calpain 2 also called $\mathrm{m}$-Calpain is a family of calcium dependent proteases that play an important role in cell migration by exerting its proteolytic activity on several FA proteins such as talin, vinculin, paxillin and FAK $[15,16]$. FA proteins are required to maintain the stability of the actin and integrin assembly [15], and play an important role in cell migration [16]. Although calcium activates calpain, it has also been shown that NO can also regulate the activity of the latter [17]. FA dynamics are considered to be an essential component of cell motility and cell migration $[18,19]$. Previous studies indicate that $\mathrm{NO}$ is involved in the maintenance and attachment of adhesions to ECM in various cell types including endothelial cells, vascular smooth muscle cells and renal meningeal cells $[20,21]$. In addition, the production of NO was shown to stimulate cell migration of intestinal epithelial cell line through FAK activation [22]. However, little attention has been given to investigate the role of $\mathrm{NO}$ in the regulation of FA turnover through affecting endocytic regulation. Since endocytosis is one of the pathways involved in the regulation of FAs dynamics, we aim to determine whether NOS inhibition has any effect on endocytosis. EEA1 positive early endosomes appear to be reduced in number and increased in size upon NOS inhibition and, interestingly, several proteins localised at the level of early endosomes are found to be S-nitrosylated. So, this paper describes some biological effects of the treatment of breast cancer cells with NOS inhibitors, including cell migration, FA turnover and early endosome distribution.

\section{Materials and methods \\ Cell lines and cell culture}

The MDA-MB-231 human invasive breast cancer cell line (ATCC $囚$ HTB-26 ${ }^{\mathrm{TM}}$ ) was purchased from the American Type Culture Collection cell bank (Manassas, VA). These cells were grown in Dulbecco's modified Eagle's medium (DMEM) containing 10\% of foetal bovine serum (Gibco ${ }^{\mathrm{TM}}, \mathrm{A} 4766801$ ) and 1\% $\mathrm{v} / \mathrm{v}$ penicillin/streptomycin $(10,000$ units/ml penicillin, $10,000 \mu \mathrm{g} / \mathrm{ml}$ streptomycin, Gibco). For optimal cell growth, these cells were incubated at $37^{\circ} \mathrm{C}$ in an atmosphere containing 95\% air, 5\% $\mathrm{CO}_{2}$ and approximately $90 \%$ humidity. These cells were tested regularly for mycoplasma with the aid of an EZPCR Mycoplasma Test kit (Geneflow, K1-0210, UK), following the manufacturer's instruction.

\section{Chemicals}

$\mathrm{N} \omega$-Nitro-L-arginine methyl ester hydrochloride (L-NAME) (Abcam, ab120136) and 1400W (Tocris Bioscience, 1415) were used to inhibit all NOS isoforms and iNOS, respectively. PAPA/NO; NOC-15; 1-(3-aminopropyl)-2-hydroxy-3-oxo-1-propyltriazan (PAPA NONOate) (Santa Cruz, 146672-58-4) was used as the NO donor. L-NAME ( $5 \mathrm{mM}), 1400 \mathrm{~W}$ $(2 \mathrm{mM})$ and PAPA NONOate $(50 \mu \mathrm{M})$ were diluted in phosphate buffered saline (PBS). Amilorid (50 $\mu \mathrm{M})$, Pitstop $2(25 \mu \mathrm{M})$ and Dynasore $(20 \mu \mathrm{M})$ were diluted in dimethyl sulphoxide (DMSO). The vehicle used in control conditions was either PBS or DMSO $(0.5 \%)$.

\section{Cell treatment with NOS inhibitors and PAPA NONOate}

MDA-MB-231 breast-cancer cells ( 1 x $10^{5}$ cells/ $\mathrm{ml}$ ) were seeded on a 6-well-plate and were left to incubate overnight under culture conditions men- 
tioned above. These cells were subsequently treated for 24 hours with PBS (vehicle), NO synthase inhibitors such as L-NAME or $1400 \mathrm{~W}$ or a nitric oxide donor (PAPA NONOate). Live imaging was used to monitor cell migration; an image was taken every 15 minutes for a period of 24 hours. The speed of migration was calculated as a total traveling distance divided by 24 hours.

\section{Cell tracking assay}

MDA-MB-231 breast-cancer cells ( 1 x $10^{5}$ cells/ $\mathrm{ml}$ ) were seeded on a 6-well-plate and were left to incubate overnight under the culture condition mentioned above. These cells were subsequently treated for 24 hours with the vehicle, L-NAME (5 $\mathrm{mM}), 1400 \mathrm{~W}(2 \mathrm{mM})$ and PAPA NONOate $(50 \mu \mathrm{M})$. Live-cell imaging was performed to monitor cell migration with a time-lapse microscope (Nikon Eclipse TiE); an image was taken (at $10 \mathrm{x}$ magnification) every 15 minutes over a period of 24 hours using the Nikon Eclipse TE200 running NIS elements software and a Nikon DXM1200 camera. The MtrackJ tool of the Image J software was used to determine the total distance covered by individual cells. The speed of migration (expressed in $\mu \mathrm{m} /$ hour) was calculated as a total distance covered by individual cells divided by 24 hours.

\section{Wound healing assay}

MDA-MB-231 breast-cancer cells ( 1 x $10^{5}$ cells/ $\mathrm{ml}$ ) were plated onto a 6-well-plate and were grown to $90 \%$ confluence. The medium was removed, a 200 $\mu \mathrm{l}$ pipette tip was used to introduce several wound lines by scratching the cell monolayer. Thereafter, cells were washed three times and incubated in DMEM containing either the vehicle, L-NAME, $1400 \mathrm{~W}$ or PAPA NONOate. The width of the wound was determined immediately after the addition of the DMEM ( $\mathrm{t}=0$ hour) and 24 hours later, using the Nikon Eclipse TiE microscope. Images of the wound lines were taken at $10 \mathrm{x}$ magnification. The percentage of covered area of the wound after 24 hours was calculated as (Average initial area, $t=0$ hour $)$ - (Average final area, $\mathrm{t}=24$ hours) $\mathrm{x} 100$.

\section{FA turnover assay}

24-hours prior to transfection, MDA-MB-231 cells were seeded $\left(1 \times 10^{4}\right.$ cells $\left./ \mathrm{mm}^{2}\right)$ onto $35 \mathrm{~mm}$ ibidi culture dishes treated with $2 \mathrm{mg} / \mathrm{ml}$ collagen (BD Bioscience, 354236). The cells were left to incubate overnight in order to allow their attachment onto the bottom of the plate. These cells were subsequently transfected with $3 \mu \mathrm{g}$ plasmid DNA consisting of zyxin-mCherry and with the aid of the TurboFect $^{\mathrm{TM}}$ transfection reagent (Thermo Scientific, R0532) at a ratio of 1:1 (w/v, DNA: TurboFect). Approximately 16 hours after transfection, the cells were treated with L-NAME, $1400 \mathrm{~W}$ or the vehicle for 10 minutes. A live-cell imaging was performed at $100 \mathrm{x}$ magnification using confocal microscopy (Nikon A1R). Cells were imaged at the low power excitation laser beam at a wavelength of $488 \mathrm{~nm}$ and $568 \mathrm{~nm}$. Images were taken every 5 seconds for 10 minutes to monitor the full lifetime of zyxin assembly and disassembly. The average life-time of zyxin was determined with ImageJ.

\section{Transferrin and dextran uptake assays}

To differentiate the endocytotic pathways, it is important to perform the transferring and dextran uptake assay. Cells ( 1 x $10^{5}$ cells $/ \mathrm{ml}$ ) were seeded in 6 well plates upon which glass coverslips were placed. After an overnight culture, the cell reached approximately $70 \%$ confluence, the medium supplemented with foetal bovine serum was replaced with serum free DMEM. These cells were incubated for 3 hours at $37^{\circ} \mathrm{C}$ in a humidified atmosphere containing $95 \%$ air and $5 \% \mathrm{CO}_{2}$ and were subsequently treated with the vehicle (PBS or DMSO), L-NAME (5 mM), 1400W (2 mM), PAPA NONOate $(50 \mu \mathrm{M})$, Amilorid $(50 \mu \mathrm{M})$, Pitstop $2(25 \mu \mathrm{M})$ and Dynasore $(20 \mu \mathrm{M})$ for 48 hours. Thereafter, the medium of the cells was replaced with serum free DEMEM containing either transferrin conjugated to Alex Fluor 546 (Thermo Fisher, T13342) (25 $\mu \mathrm{g} / \mathrm{ml}$ ) or dextran conjugated to fluorescein (Thermo Fisher, D1820) (500 $\mu \mathrm{g} / \mathrm{ml})$ and was left to incubate for 30 minutes. The cells were washed twice with ice-cold PBS then fixed with 4\% paraformaldehyde (Sigma Aldrich) diluted in PBS $\left(4^{\circ} \mathrm{C}\right)$. The cells were washed 3 times with ice-cold PBS and were subsequently treated with an acidic buffer (1M Glycine, $150 \mathrm{mM}$ $\mathrm{NaCl}, \mathrm{pH} 3$ ). The acidic washing step was performed to strip away transferrin/dextran that are bound to the cell surface, since endocytosis blocked at an intermediate stage will cause transferrin/dextran accumulation on the plasma membrane which in turn will affect the total fluorescence measured in the cell. The cells were permeabilised for 10 minutes with PBS containing $0.5 \%$ Triton X-100 and were washed 3 times with ice-cold PBS. Confocal images were taken at different layers of the cell (z-stacks) with a resolution of $1024 \times 1024$ pixels in order to capture transferring or dextran uptake. The brightness \& contrast were then adjusted using ImageJ, then the fluorescence intensity of transferrin and dextran was measured. Alexa Fluor 546 channels and laser power were adjusted as the following values: HV: 64, Offset: 0 and Alexa Fluor $546 \mathrm{~nm}: 6.35$ for all the experiments. Using ImageJ, the region of interest was selected around the cell and the relative intensity of transferrin or dextran was quantified and subtracted from the average background fluorescence in order to determine the number and the size of endosomes containing dextran or transferrin. 


\section{Immunocytochemistry}

The cellular localisation of iNOS, eNOS and early endosome markers were investigated by immunostaning. Cells were incubated (at $37^{\circ} \mathrm{C}$ ) overnight in 6 -well plates containing glass coverslips. Thereafter, the growth medium was discarded and replaced with media containing the inhibitors or the NO donor depending on the experiments. After 24 hours, the cells were washed in PBS and fixed for 15 minutes in $4 \%$ paraformaldehyde (PFA) in PBS at room temperature. To permeabilised these fixed cells, the excess PFA was washed away with PBS and the cells were incubated at room temperature for 10 minutes in PBS containing 0.5\% Triton X-100. These cells were subsequently treated with PBS containing $10 \%$ goat serum for 30 minutes at room temperature. Antibodies raised against EEA1 (Cell Signalling, \#2411S), eNOS (Cell Signalling, \#9572S) or iNOS (Abcam, ab3523) diluted to 1:100 in PBS containing $2 \%$ goat serum were added to the cells and incubated for 60 minutes at room temperature. Unbound antibodies in excess were washed away with PBS and the cells were transferred into a box where they were protected from light. Secondary antibodies conjugated with Alexa Fluor 546 or 488 (Cell signalling, \#44125, \#4408S) diluted to 1:200 in PBS containing $2 \%$ goat serum were added to the cells and incubated for 30-60 minutes at room temperature. These cells were washed with PBS and were visualised using confocal microscopy.

\section{FA and endosomes analysis}

The number and the size of FAs and endosomes were analysed on fixed cells. All images were acquired with a confocal microscopy (Nikon Eclipse Ti Laser-scanner), at 100x magnification and a resolution of $1024 \times 1024$ pixels using the Nikon confocal system software. Images taken at depths where both endosomes and FA were both present. The acquired images were processed by subtracting the background; the average number and size of both FA and endosomes were determined with Image J. To investigated whether the localisations of FA and endosomes were correlated, the Spearman's rank correlation coefficient was determined within a selected region of interest using ImageJ.

\section{Biotin switch assay and western blotting}

The potential link between early endosomes and NO were investigated using two methods; Biotin switch assay and western blotting to detect whether early endosomes proteins were S-nitrosylated. S-nitrosylated cysteine residues were detected with the S-nitrosylated Protein Detection kit from (Cayman Chemical, 75816-684), following the manufacturer's instruction. After cells were washed twice with $5 \mathrm{ml}$ ice-cold PBS, they were removed from the flask then centrifuged at $500 \mathrm{~g}$ for 5 minutes at $4^{\circ} \mathrm{C}$. Cell pellets were resuspended with $0.5 \mathrm{ml}$ buffer $\mathrm{A}$, containing a blocking reagent, and were incubated for 30 minutes at $4^{\circ} \mathrm{C}$ under mild agitation. $2 \mathrm{ml}$ of ice-cold $70 \%$ acetone (diluted in deionised distilled $\mathrm{H}_{2} \mathrm{O}$ ) was added to the resuspended cells and were left to incubate at $-20^{\circ} \mathrm{C}$ for 1 hour. The samples were subjected to centrifugation at $3000 \mathrm{~g}$ for 10 minutes $\left(4^{\circ} \mathrm{C}\right)$ and the pellets were resuspended and incubated for 1 hour at room temperature in buffer B, containing reducing and labelling reagents. $2 \mathrm{ml}$ of ice-cold $70 \%$ acetone (diluted in deionised distilled $\mathrm{H}_{2} \mathrm{O}$ ) was added to the samples and incubated at $-20^{\circ} \mathrm{C}$ for 1 hour. The pellets were retained following a centrifugation at $3,000 \mathrm{~g}$ for 10 minutes $\left(4^{\circ} \mathrm{C}\right)$. After the resuspension of the pellet in ice-cold PBS $(100 \mu \mathrm{l})$, the cells were lysed overnight at $4^{\circ} \mathrm{C}$ with $100 \mu \mathrm{l}$ of RIPA buffer, containing streptavidin-agarose bead $(20 \mu \mathrm{l})$. The samples were subsequently centrifuged at $14,000 \mathrm{~g}$ for 30 seconds (at $4^{\circ} \mathrm{C}$ ) and the pellets were washed three times with $300 \mu \mathrm{l}$ with RIPA buffer. Following the streptavidin pulldown, the samples were denatured at $95^{\circ} \mathrm{C}(5 \mathrm{~min}-$ utes) in reduced laemmli buffer containing $2.5 \%$ $\beta$-mercaptoethanol. Samples treated with $100 \mu \mathrm{M}$ mercury chloride $\left(\mathrm{HgCl}_{2}\right)$ to cleave S-NO bonds in proteins prior to the assay to serve as negative control for the assay. Proteins in the samples were separated by sodium dodecyl sulfate-polyacrylamide gel electrophoresis (SDS-PAGE), then transferred onto a polyvinylidenedifluoride (PVDF) membrane. The PVDF membrane was incubated for 1 hour at room temperature in a blocking solution made up of 5\% dry milk solubilised in Tris-Buffered Saline Tween (TBST). The membranes were subsequently washed three times in TBST (10 minutes each time) and were incubated overnight at $4^{\circ} \mathrm{C}$ under mild agitation with primary antibodies such as anti-Rab5 (Cell Siganlling, \#3547), anti-EEA1 (Cell Signalling, \#3288), anti-APPL1 (Cell signalling, \#3858), anti-H2B (Abcam, ab52484) and anti-GAPDH (Sigma, G8795) diluted in either 5\% dry milk or $5 \%$ BSA solubilised in TBST $(1: 1000)$. The membranes were washed three times in TBST (10 minutes each time) and incubated for 1 hour at room temperature under agitation with horseradish peroxidase-conjugated antibodies raised against mouse (1:2500, in $5 \%$ of dry milk) and rabbit (1:2500, in $5 \%$ of dry milk) IgGs (Sigma-Aldrich, AP306P, AP307P). The membranes were subsequently washed three times with TBST (10 minutes each time) and an enhanced chemiluminescence solution was added to the membrane. Images of the immunoreaction were acquired using the ImageQuant LAS 4000 imager (GE Healthcare Life Sciences) and Image Quant TL software.

\section{Bioinformatic analysis}

GPS-SNO and IntFOLD tools were used to identify buried and exposed cysteines residue in proteins in order to determine what residue which is most likely to be S-nitrosylated. Three dimensional structural models of human early endosomal proteins 
such as EEA1, APPL1 and Rab5 were generated with the IntFOLD server $[23,24]$. GPS-SNO analysis was used identify cysteines residues in each protein. Accessibility of cysteine residues within the protein three-dimensional structure was assumed to determine a potential to be S-nitrosylated. The GPS-SNO S-nitrosylation site prediction algorithm was used to predict the specific cysteine residue that is likely to be S-nitrosylated [25]. The prediction algorithm was applied to APPL1, EEA1, Rab5 and other proteins including $\mathrm{H} 2 \mathrm{~B}$ and ubiquitin.

\section{Statistical analysis}

The data obtained by the imaging software were statistically analysed with GraphPad prism 5 software (GraphPad software, San Diego, CA). One-way analysis of variance (ANOVA) was performed on data resulting from experiment comprising three or more experimental groups. Following a significant difference identified via ANOVA, a Dunnett's post-hoc test was used for pairwise comparisons in order to compare each treatment to a single control (vehicle). All results were obtained from at least three independent experiments in triplicate $(n=3)$. A value of $p$-value $\leq 0.05$ was considered statistically significant.

\section{Results}

Effect of NOS inhibitors and a NO donor on cell migration and FA turnover

To evaluate the effect of NO on cell migration, a wound healing assay and a cell tracking assay was employed on MDA-MB-231 cells treated with the iNOS inhibitor $1400 \mathrm{~W}$ or the whole NOS inhibitor L-NAME or the NO donor PAPA NONOate. Our results showed that cells treated with L-NAME or $1400 \mathrm{~W}$ displayed a reduced covering area 24 hours after scratching (Fig. 1A and 1B). PAPA NONOate showed no effect on wound-healing (Fig. 1A and 1B). As shown in figure 1C, the speed of cell migration was reduced in cells treated with L-NAME (17.1 $\pm 0.7 \mu \mathrm{m} /$ hour, $\mathrm{p}<0.01)$ and $1400 \mathrm{~W}(19.0 \pm 1.3 \mu \mathrm{m} /$ hour, $\mathrm{p}<0.05)$ compared to that of vehicle-treated cells (23.5 $\pm 0.8 \mu \mathrm{m} /$ hour). However, PAPA NONOate exhibited no effect on the speed of cell migration $(23.4 \pm 0.3 \mu \mathrm{m} /$ hour, $\mathrm{p}>0.05)$. Next, we investigated whether the inhibition of NOS or iNOS, as well as the addition of NO, can affect FA turnover. Cells transfected with zyxin-mCherry displayed a prolonged duration of FA turnover when treated with L-NAME $(51.2 \pm 2.0$ seconds, $\mathrm{p}<0.05)$ or $1400 \mathrm{~W}(48.8 \pm 2.3$ seconds, $\mathrm{p}<0.05)$ compared to vehicle-treated cells
A

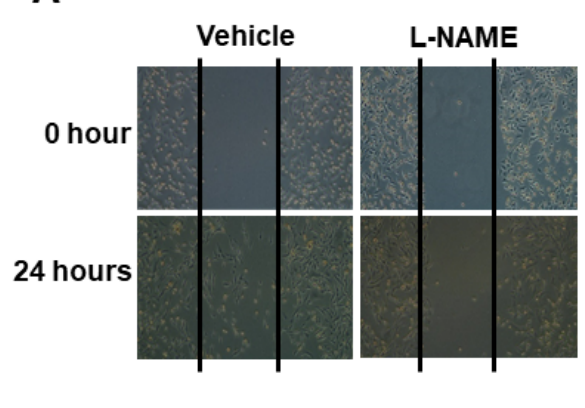

C

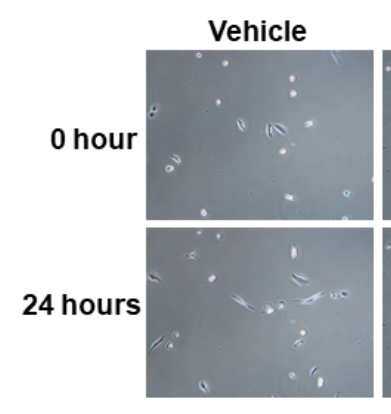

L-NAME

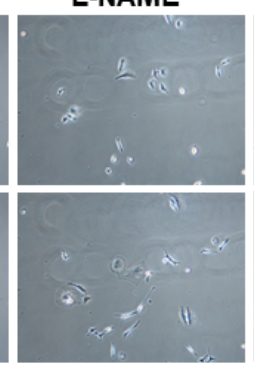

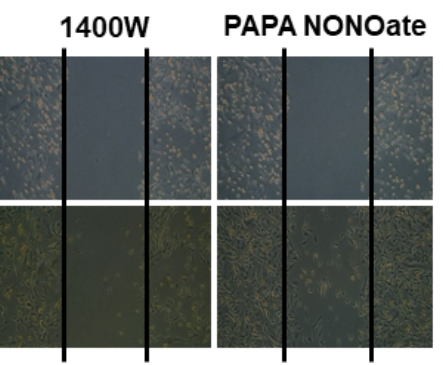

B

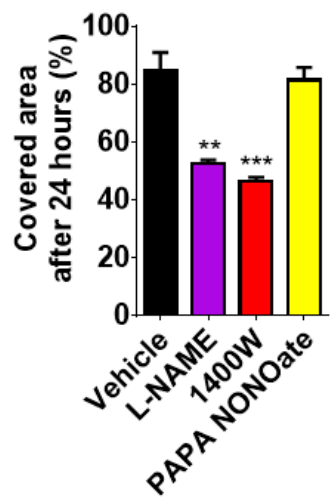

D

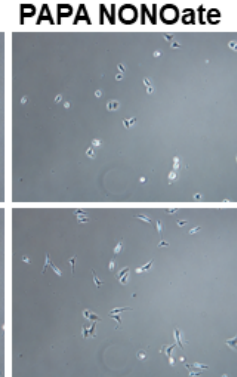

1400W

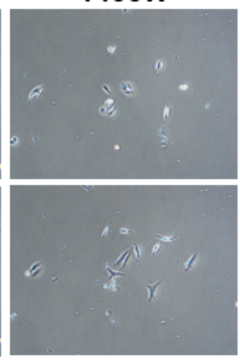

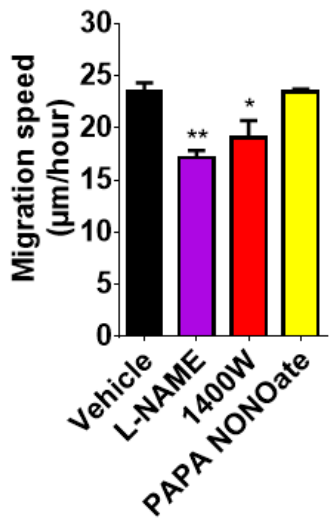

FIGURE 1 Effect of NO inhibitors or NO donors on cell migration. cells were treated with the vehicle, for 24 hours. (A) Representative wound-healing assay images for MDA-MB-231 cells treated with the vehicle (0.5\% PBS), L-NAME (5 mM), $1400 \mathrm{~W}(2 \mathrm{mM})$ or PAPA NONOate $(50 \mu \mathrm{M})$. Images were taken at 0 and 24 hours to wound closure (the lines show wound edges). (B) Bar plot representing quantitative analyses of total covered area at 24 hours after scratching. (C) Representative images of migration assay showing cell tracking after a 24-hour period using a time-lapse microscope. (D) Bar plot representing quantitative analyses of migration speed. The data shown here are representative of three independent experiments; 40 cells were analysed in each experiment. Dunnett's test comparison test was performed following a confirmed statistical difference using one-way ANOVA. ${ }^{*} \mathrm{p}<0.05,{ }^{* *} \mathrm{p}<0.01$ and ${ }^{* * *} \mathrm{p}<0.01$. Results are presented as mean \pm SEM 
(36.0 \pm 3.8 seconds), while PAPA NONOate had no effect on the FA turnover (38.3 $\pm 1.7, \mathrm{p}>0.05)$ (Fig. 2A and $2 B$ ).

Effect of NOS inhibitors on transferrin and dextran internalisation

To examine the effect of NOS inhibitors on two endocytotic pathways, namely endocytosis or micropinocytosis, we measured the uptake of transferrin and dextran in MDA-MB-231 cells treated with L-NAME and $1400 \mathrm{~W}$. As shown in figure $\mathbf{3 A}$ and $\mathbf{3 B}$, the inhibition of micropinocytosis with Amiloride as well as the inhibition of dynamin (Dynasore) and clathryn-dependent endocytosis (Pitstop 2) reduced the uptake of transferrin and dextran. The number of vesicles containing transferrin decreased with Amiloride, Dynasore and Pitstop 2 treatment. Cells that were treated with Amiloride and Pitstop 2 exhibited a decreased number of vesicles containing dextran, while those treated with Dynasore showed an increased number of vesicles containing dextran. Regarding the size of vesicles containing transferrin or dextran, neither Amiloride nor Dynasore nor Pitstop 2 had an effect. Both L-NAME and 1400W did not affect transferrin and dextran uptake, since the intensity of fluorescence of transferrin and dextran did not change in L-NAME (433.0 \pm 37.8 arbitrary unit) and 1400W (447.3 \pm 3.8 arbitrary unit) treated cells compared to vehicle-treated cells (421.3 \pm 55.2 arbitrary unit)
(Fig. 3C and 3D). Similarly, these NOS inhibitors did not change the number of vesicles containing dextran and transferrin as the number of vesicles containing transferrin and dextran in cells treated with L-NAME $(22 \pm 1)$ and 1400W $(19 \pm 2)$ did not differ from that of vehicle-treated cells ( $23 \pm 2$ ) (Fig. 3C and 3D). The size of vesicles containing transferrin and dextran were found to be comparable across cells treated with L-NAME $\left(1.5 \pm 0.1 \mu \mathrm{m}^{2}\right), 1400 \mathrm{~W}\left(1.7 \pm 0.2 \mu \mathrm{m}^{2}\right)$ or the vehicle $\left(1.7 \pm 0.1 \mu \mathrm{m}^{2}\right)$ (Fig. $3 \mathrm{C}$ and 3D).

\section{Effect of NOS inhibitors and a NO donor on early endosomes and Rab5-positive vesicles}

To examine whether NO is involved in endocytosis regulation through early endosomal compartments, the impact of NOS inhibition and exogenous NO on the number and size of EEA1-positive endosomes and Rab5-positive vesicles were assessed in MDAMB-231 cells. As shown in figure $\mathbf{4 A}$, the number of EEA1-positive endosomes was found to be lower in cells treated with L-NAME $(24 \pm 2, \mathrm{p}<0.05)$ and 1400W $(20 \pm 7, \mathrm{p}<0.05)$ compared to that vehicle-treated cells $(44 \pm 3)$. However, PAPA NONOate did not affect the number of EEA1-positive endosomes (41 $\pm 1, p>0.05)$. The analysis of the size of EEA1-positive endosomes showed that cells treated with L-NAME $\left(1.0 \pm 0.1 \mu^{2}, \mathrm{p}<0.01\right)$ or $1400 \mathrm{~W}$ $\left(1.1 \pm 0.1 \mu \mathrm{m}^{2}, \mathrm{p}<0.01\right)$ exhibited an increased size of these endosomes compared to vehicle-treated cells
A
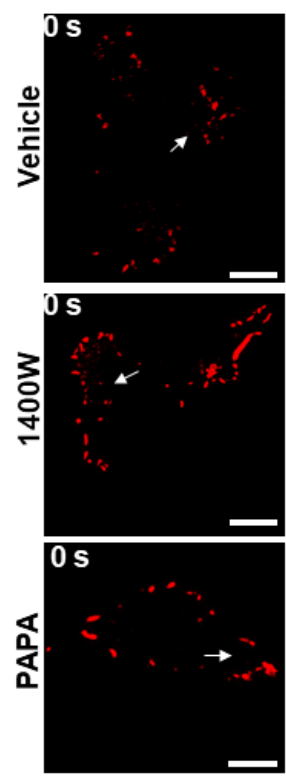
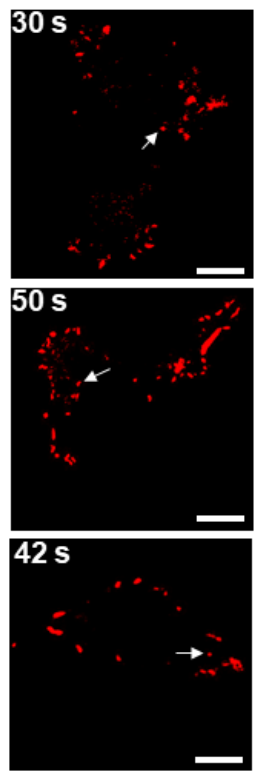
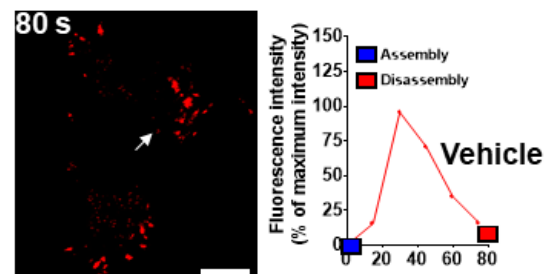

$125 \mathrm{~s}$
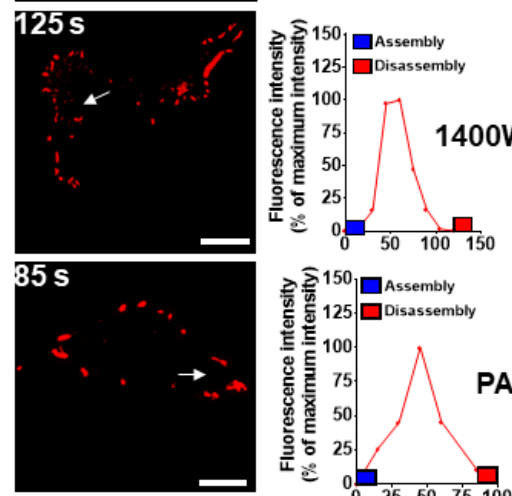

B

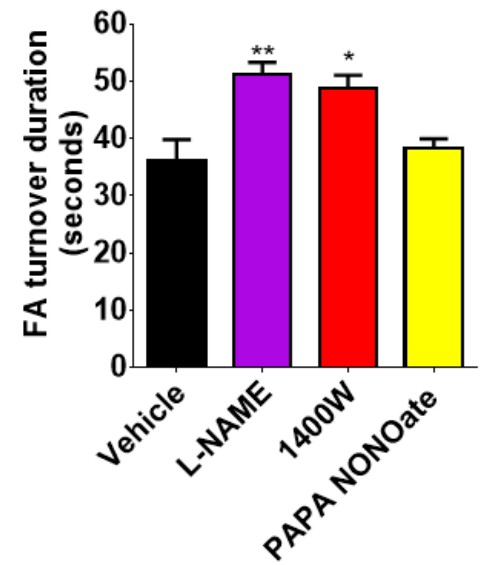

FIGURE 2 Effect of NO inhibitors or NO donors on FA turnover duration. MDA-MB-231 cells transfected with zyxin-mCherry were treated with the vehicle (0.5\% PBS), L-NAME (5 mM), 1400W (2 mM) or PAPA NONOate (50 $\mu \mathrm{M})$ for 10 minutes and were subsequently imaged using live-cell imaging. (A) Representative images showing FA assembly and disassembly. (B) Bar plot showing quantitative analyses of FA turnover duration. White arrows indicate FA. The data include three biological independent experiments; 100 zyxin-containing FA were used to assess the duration of FA turnover across 24 cells (per experiment). Dunnett's test comparison test was performed following a confirmed statistical difference using one-way ANOVA. ${ }^{*} \mathrm{p}<0.05$ and ${ }^{* *} \mathrm{p}<0.01$. Results are presented as mean \pm SEM. The scale bar represents $10 \mu \mathrm{m}$ 

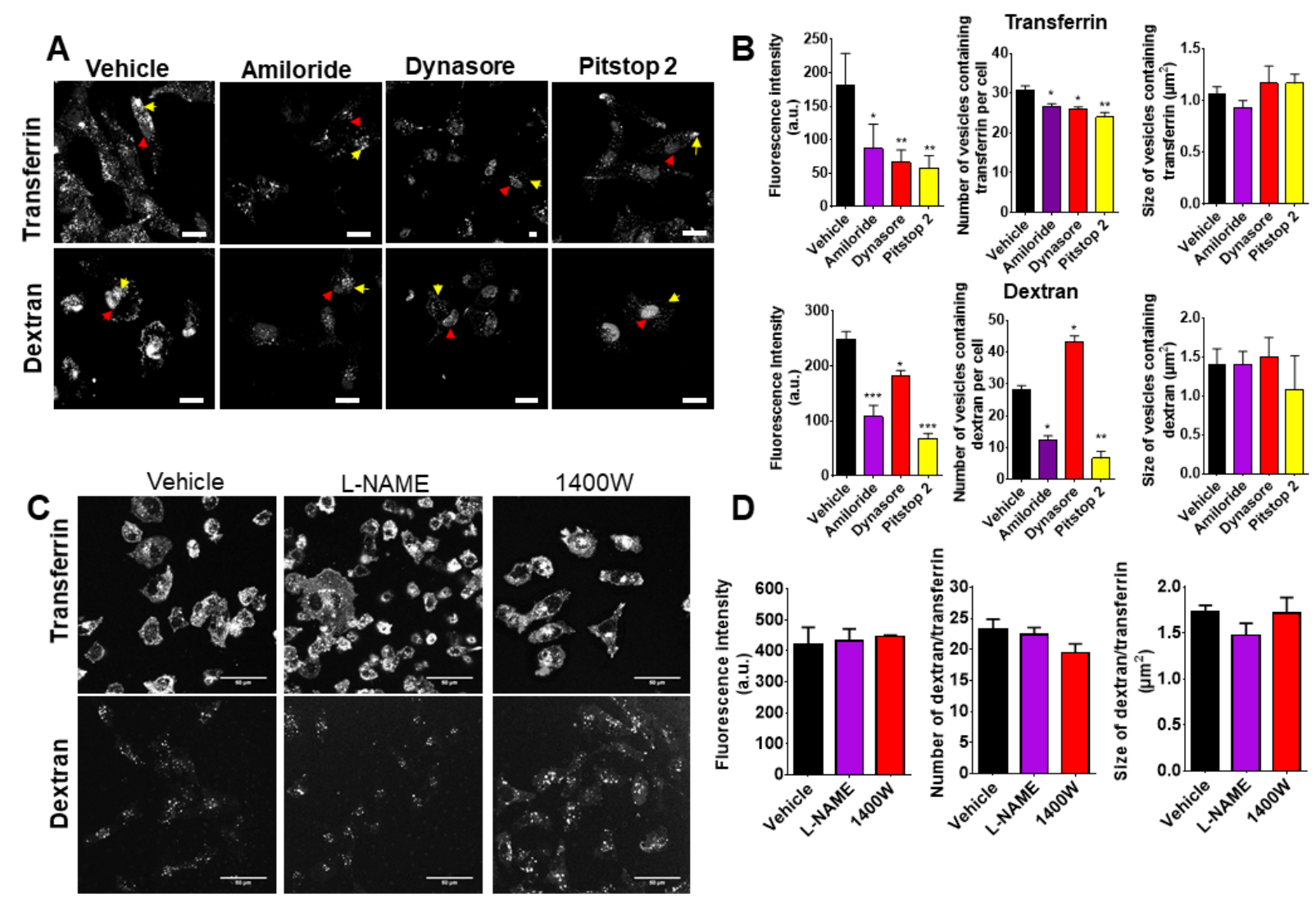

FIGURE 3 Effect of NO inhibitors on transferrin and dextran uptake. (A) Representative images of MDA-MB-231 cells treated with the vehicle $(0.5 \%$ DMSO), the micropinocytosis inhibitor Amilorid $(50 \mu \mathrm{M})$ or with endocytotic inhibitors Pitstop $2(25 \mu \mathrm{M})$ and Dynasore $(20 \mu \mathrm{M})$. After 48 hours, a transferrin/dextran uptake assay was performed using Alexa-Fluor-546-conjugated transferrin and fluorescein-conjugated dextran for 30 minutes. The scale bar represents 20 $\mu \mathrm{m}$. Red arrows indicate nuclei. Yellow arrows indicate vesicles (B) Graphs representing quantitative analysis of fluorescent intensity, number of vesicles and vesicle size containing transferrin and dextran. (C) Representative images showing a transferrin and dextran uptake assay on MDA-MB-231 cells treated with the vehicle (0.5\% PBS), L-NAME (5 mM) or 1400W ( $2 \mathrm{mM}$ ) for 48 hours. All conditions were performed as mentioned above using Alexa-Fluor-546-conjugated transferrin and fluorescein-conjugated dextran for 30 minutes. The scale bar represents $50 \mu \mathrm{m}$. (D) Bar plots representing quantitative analysis of intracellular fluorescent intensity, the number and the size of dextran/transferrin-containing vesicles following L-NAME and 1400W treatment. Results are presented as mean \pm SEM. Dunnett's test comparison test was performed following a confirmed statistical difference using one-way ANOVA. ${ }^{*} \mathrm{p}<0.05,{ }^{* *} \mathrm{p}<0.01$ and ${ }^{* * *} \mathrm{p}<0.01$

$\left(0.5 \pm 0.1 \mu \mathrm{m}^{2}\right)$. The size of EEA1-positive endosomes did not differ between cells treated with PAPA NONOate $\left(0.8 \pm 0.1 \mu \mathrm{m}^{2}, \mathrm{p}>0.05\right)$ and that of vehicle-treated cells (Fig. 4A). Next, investigate the effect of NOS inhibition on the number and size of Rab5-positive vesicles. Our results in figure 4B showed that both L-NAME and 1400W inhibitors exerted no effect on the number of Rab5-positive vesicles since the number of Rab5-positive vesicles was not affected in cells treated with L-NAME $(35 \pm 1)$ or $1400 \mathrm{~W}(36 \pm 1)$ compared to vehicle-treated cells $(33 \pm 1)$. The size of Rab5-positive vesicles was not affected as a result of L-NAME $\left(1.2 \pm 0.1 \mu \mathrm{m}^{2}\right)$ or $1400 \mathrm{~W}\left(1.5 \pm 0.2 \mu \mathrm{m}^{2}\right)$ treatment, since the size of Rab5-positive vesicles in vehicle-treated cells was found to be $1.4 \pm 0.2 \mu \mathrm{m}^{2}$.

\section{Localisation of eNOS, iNOS and EEA1-positive endosomes}

Given that in our previous results, we demonstrated that the inhibition of NOS regulates the number and the size of EEA1-positive endosomes, we sub- sequently investigated whether the localisation of EEA1-positive endosomes and that of eNOS or iNOS correlates using immunocytochemistry on fixed MDA-MB-231 cells. As shown in figure 5A, the localisations of EEA1 and eNOS were found to be correlated, as the correlation coefficient was found to be 0.64 \pm 0.17 . Similarly, the correlation coefficient between the localisations of EEA1 and iNOS was $0.63 \pm 0.11$.

\section{S-nitrosylation of proteins in early endosomes}

Following the investigation of the localisation of eNOS and iNOS in relations to EEA1, we assessed the S-nitrosylation of proteins implicated in the formation of early endosomes using the biotin switch assay. The Analyses by western blot revealed that non-S-nitrosylation proteins such as H2B or ubiquitin were not detected by the assay (Fig. 5B). Our data showed the early endosomal proteins such as APPL1, EEA1 and Rab5 were found to be $\mathrm{S}$-nitrosylated. To ensure that the S-nitrosothiols group on these proteins were accurately detected, 


\section{A}
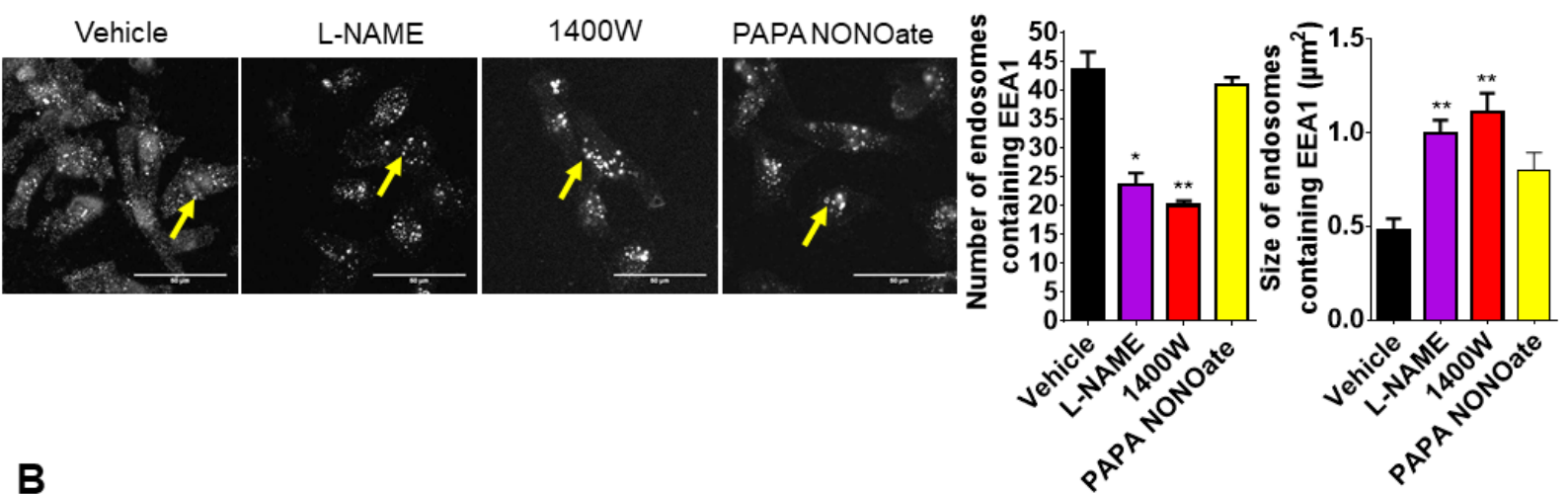

B
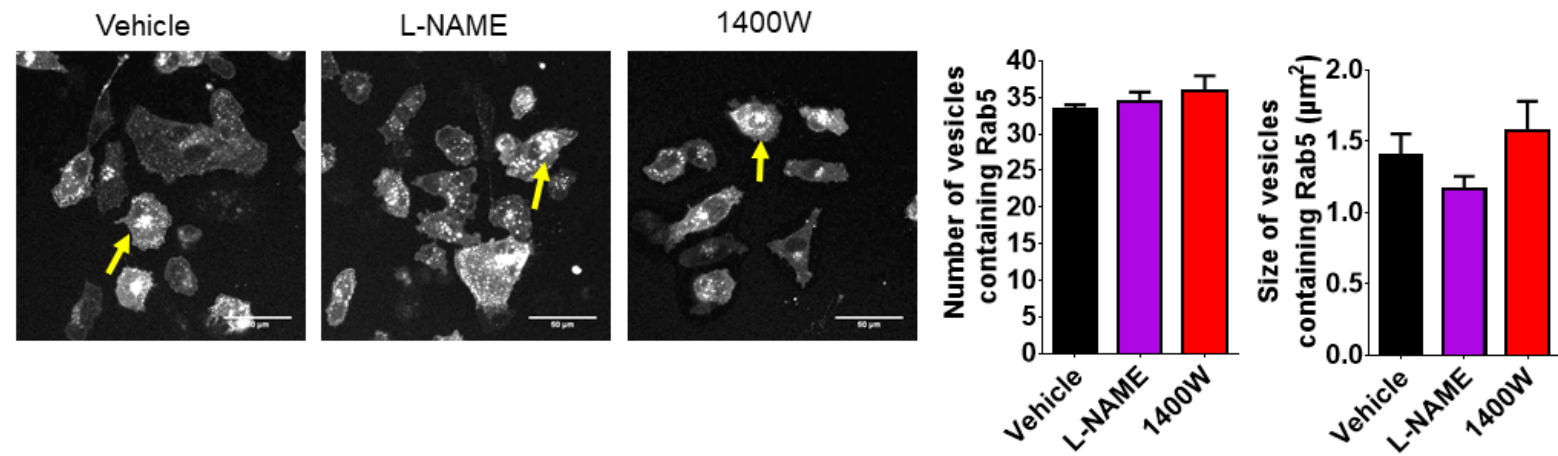

FIGURE 4 The effect of NOS inhibitors on EEA1-containing endosomes and Rab5-containing vesicles in MDA-MB-231 cells. Cells were treated with vehicle or different nitric oxide inhibitors (L-NAME, 1400W) and PAPA NONOate for 48 hours, fixed and were stained with anti-Rab5 and anti-EEA1 antibodies. (A) Effect of L-NAME, 1400W and PAPA NONOate on the number and size of EEA1-positive endosomes. (B) Effect of L-NAME, 1400W and PAPA NONOate on the number and size of Rab5-positive vesicles. Yellow arrows indicate EEA1-positive endosomes and Rab5-positive vesicles. The scale bar represents $50 \mu \mathrm{m}$. One-way ANOVA with Dunnett's multiple comparison test were used to compare each treatment with the control. Results are presented as mean \pm SEM. The data include three independent experiments, in each experiment consisted of at least 80 cells that were analysed. Statistical significance differences were accepted at ${ }^{*} \mathrm{p}<0.05$ and ${ }^{* *} \mathrm{p}<0.01$

the lysates were treated with $\mathrm{HgCl}_{2}$ to cleave $\mathrm{S}-\mathrm{NO}$ bonds prior the biotin switch assay. As a result, $\mathrm{HgCl}_{2}$ treated lysates showed no immunoreaction in all evaluated proteins (Fig. 5B).

\section{Bioinformatic analysis of S-nitrosylation in} endosomal proteins

Once it was ascertained that early endosome markers were S-nitrosylated, a bioinformatic analysis that uses the GPS-SNO algorithm was performed on APPL1, EEA1, Rab5 and other proteins including $\mathrm{H} 2 \mathrm{~B}$ and ubiquitin in order to predict cysteine residues with the potential to be subjected to S-nitrosylation. The results showed that APPL1 presented two potential cysteine sites at position 99 and 603 that could be S-nitrosylation; four cysteine sites at position 46, 255, 894 and 1102 were identified in EEA1; a single cysteine site for potential S-nitrosylation was found in Rab5, at position 212. However, both H2B and ubiquitin expectedly showed no potential sites for S-nitrosylation (Fig. 5B). Next, we used the IntFOLD software to generate three-dimensional models of early endosome proteins. The tool was subsequently used to identify cysteine residues that are easily accessible, therefore most likely to be S-nitrosylated. As shown in figure 6, the three-dimensional structure of EEA1 showed that two cysteine residues, at position 255 and 1102, are hidden within the structure of the protein, thus suggesting that these sites are not likely to be subjected to S-nitrosylation. Concerning the other two cysteine residues, at position 46 and 894, they appear to be exposed, suggesting that these cysteine sites could be S-nitrosylation. The three-dimensional model of Rab5 showed that the cysteine residue, at position 212 was located in an accessible area of the protein, therefore would be likely S-nitrosylated (Fig. 7). However, a three-dimensional model for APPL1 indicated that the location of both cysteine residues was hidden and thus would be unlikely to be S-nitrosylated (Fig. 8).

\section{Discussion}

Given that NO contributes to cell migration in invasive tumours [1], here we investigated the potential role of NO and protein S-nitrosylation on cell migration and FA turnover, using a pharmacological approach. NOS inhibitors L-NAME and 1400W 
A
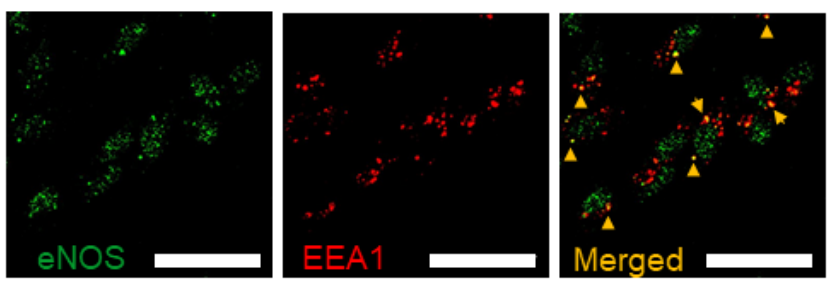

B
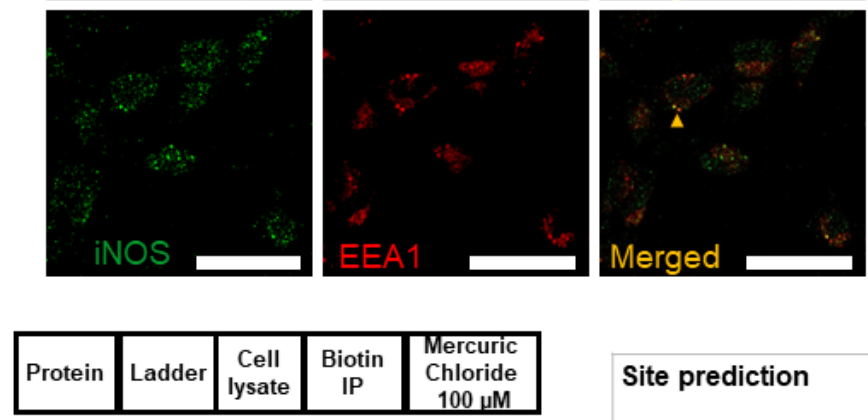

\begin{tabular}{|c|c|}
\hline Site prediction & $\begin{array}{l}\text { Positions of cysteine } \\
\text { residue and score }\end{array}$ \\
\hline $\begin{array}{l}\text { - VIDELSSCHAVLSTQ } \\
\text { - ESNLSSVCYIFESN }\end{array}$ & $\begin{array}{l}\text { Position } 99(2.4) \\
\text { Position } 603(20.7)\end{array}$ \\
\hline $\begin{array}{l}\text { - EGFICPQCMKSLGSA } \\
\text { - SEKLKDECKKLQSQY } \\
\text { - ILDLEKTCKELKHQL } \\
\text { - EQQLQERCKALQDIQ }\end{array}$ & $\begin{array}{l}\text { Position } 46(2.4) \\
\text { Position } 255(2.0) \\
\text { Position } 894(1.6) \\
\text { Position } 1102(2.2)\end{array}$ \\
\hline - TQPTRNQCCSN & Position 212 (3.3) \\
\hline No site predicted & None \\
\hline No site predicted & None \\
\hline
\end{tabular}

Ubiquitin

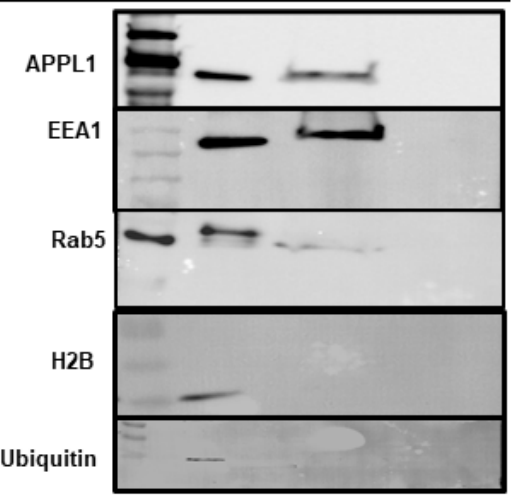

FIGURE 5 Cellular localisation of eNOS and iNOS with EEA1. (A) Confocal images of the localisation between eNOS and EEA1 and between iNOS and EEA1. Immunocytochemistry was performed on fixed cells. The correlation between the localisation of eNOS (green) and EEA1 (red) and between the localisation of iNOS (green) and EEA1 (red) was determined with the Spearman's (rho) correlation coefficient. Yellow arrows indicate regions of co-localisation. Three independent experiments were performed. (B) S-nitrosylation of early endosomal proteins. Representative immoblotting images showing S-nitrosylation in early endosomal proteins (EEA1, Rab5A and APPL1). No S-nitrosylation was found in nuclear proteins (H2B) and ubiquitin. MDA-MB-231 cell lysate treated with $100 \mu \mathrm{M} \mathrm{HgCl} 2$ displayed no S-nitrosylated proteins. Three independent experiments were performed. List of proteins with cysteine residues (highlighted in red) with predicted S-nitrosylation

have been shown to inhibit protein S-nitrosylation $[26,27]$. Our result showed that the speed of cell migration and the duration of FA turnover were slowed down and reduced, respectively in cells treated with L-NAME or $1400 \mathrm{~W}$ (Fig. 1). Unexpectedly, PAPA NONOate, a NO donor found to induce protein S-nitrosylation $[28,29]$, was shown to exert no effect on cell migration and FA turnover, at the concentration used in this study (Fig. 1 and 2). There are two scenarios that could explain this lack of effect. (1) All proteins that could be subjected to S-nitrosylation and are implicated in the regulation of cell migration and FA turnover, may already be S-nitrosylated under our experimental condition. As a result, an exogenous supply of NO cannot further increase the proportion of s-nitrosylated proteins. (2) The concentration of PAPA NONOate may be too low for these cells to induce protein S-nitrosylation. In order to unambiguously determine the impact of exogenous NO on cell migration and FA turnover duration, it will be necessary to use either higher concentrations of PAPA NONOate or other NO donors with longer half-life (e.g. SNAP and DETA-NONOate), while comparing NO levels and protein S-nitrosylation to non-treated cells [30].

Endocytic processes have been shown to regulate FA turnover [31]. In this study, we investigated the effect of L-NAME and 1400W on transferrin and dextran uptake. NO has been reported to S-nitrosylate dynamin and this in turn promotes cell survival and endocytosis [32]. Furthermore, it has been shown that NO nitrosylates dynamin within its pleckstrin homology (PH) domain on a cystein residue located at position 607 (Cys-607) [12]. The S-nitrosylation of dynamin at Cys-607 induces dynamin oligomerisation and its associated GTPase activity, which in turn leads to increased receptor mediated endocytosis [12,32]. For example, HEK293 cells overex- 
A

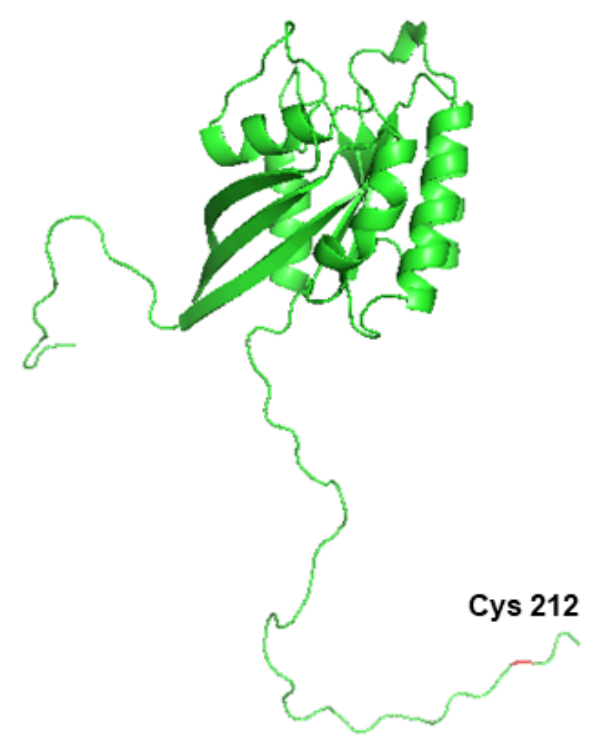

B

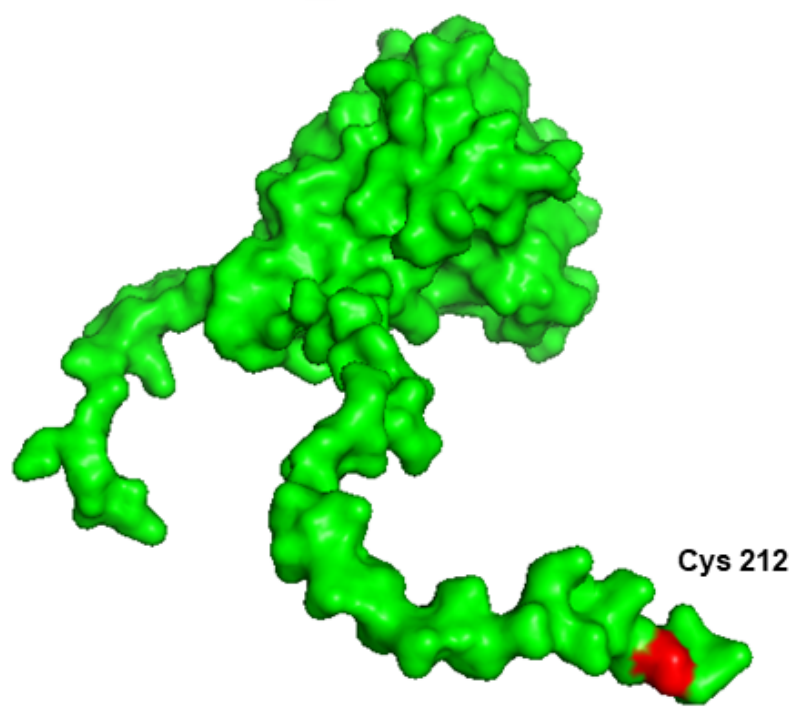

FIGURE 6 A three-dimensional model of the human EEA1 structure. (A) depicts the location of all cysteine residues (highlighted in red) in EEA1. (B) shows the location of Cys-1102 (highlighted in red). (C) shows the locations of Cys-894 and Cys-46, both highlighted in red (D) shows the location of Cys-255 (highlighted in red)

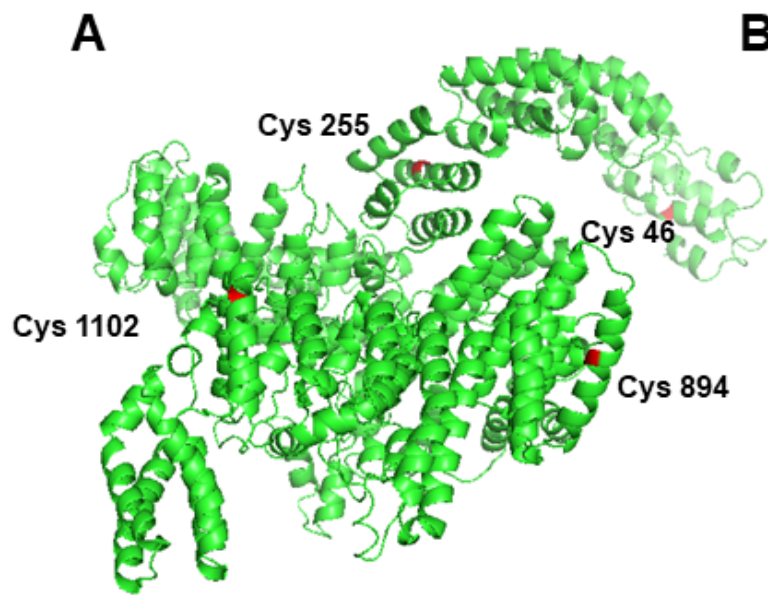

B

C
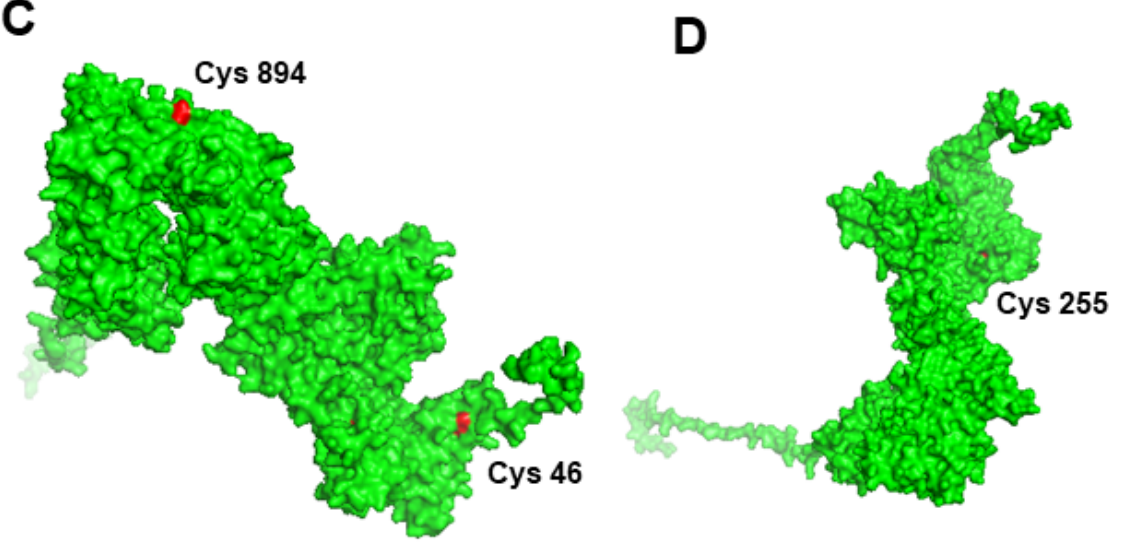

FIGURE 7 A three-dimensional model of the human Rab5. (A) depicts the location of all cysteine residues (highlighted in red) in human Rab5. (B) shows the location of Cys-212 (highlighted in red) 
A

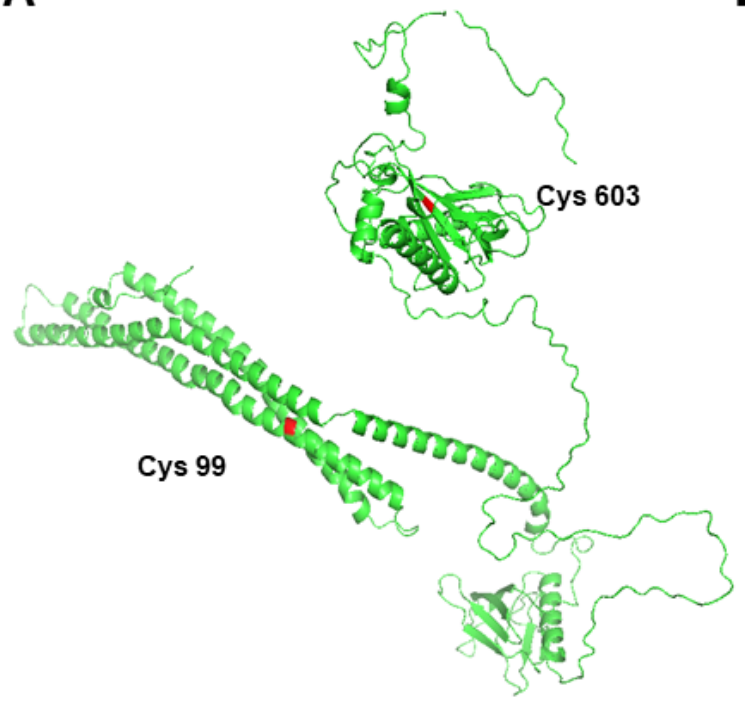

B

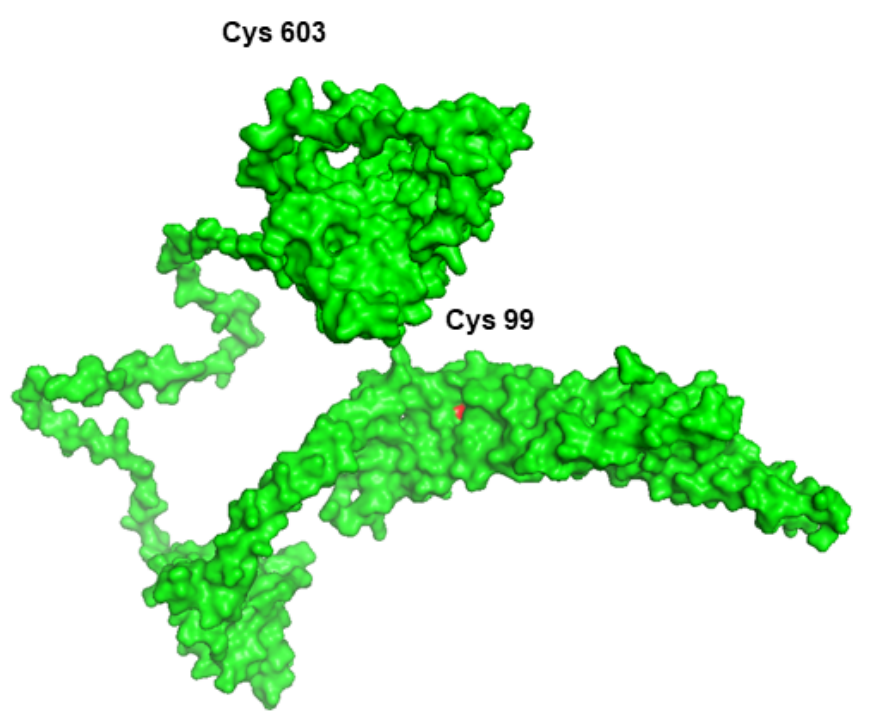

FIGURE 8 A three-dimensional model of the human APPL1. (A) depicts the position of all cysteine residues (highlighted in red) in human APPL1. (B) shows the locations of Cys-99 and Cys-603, both highlighted in red

pressing eNOS, increases $\beta 2$-adrenergic receptor internalisation [33]. Whilst transferrin and dextran are internalised through micropinocytosis and endocytosis (Fig. 3A and 3B), our data showed that L-NAME and 1400W exhibited no effect on transferrin and dextran uptake in MDA-MB-231 cells (Fig. 3C and 3D), suggesting that iNOS or NOS as a whole, is not involved in the regulation of endocytocis or micropinocytosis in MDA-MB-231 cells.

A study that examined the role of NO in the regulation membrane fusion by acting through a SNARE complex, demonstrated that NO induced the exocytosis of Weibel-Palade Bodies [34]. These findings suggest that NO regulates vesicle trafficking. As we investigated whether NO might disrupt the trafficking of endosomes, we found that the treatment of MDA-MB-231 cells with L-NAME or $1400 \mathrm{~W}$ caused a reduction in the number EEA1-positive endosomes while their size was found to increase (Fig. 4A). However, cells treated with PAPA NONOate exhibited no change in both the number and the size of EEA1-positive cells. This result is consistent with the absence of effect of PAPA NONOate on cell migration and FA turnover, which is most likely due to the same potential causes that have been previously mentioned.

In addition, we showed that the localisation of EEA1 correlates moderately with that of eNOS and iNOS (Fig. 5A). Together, this suggests that NO may regulate that the function of EEA1. We subsequently investigated whether EEA1 was targeted by S-nitrosylation using the biotin switch assay followed by western blot. Our data revealed that EEA1 was indeed S-nitrosylated (Fig. 5B). Based on the sequence analysis performed with GPS-SNO algorithm and a three-dimensional reconstruction of EEA1, it is plausible that the $\mathrm{S}$-nitrosylation may occurred on Cys-46 and Cys-894 rather than Cys-255 and Cys-1102, since the latter two were found to be hidden and hardly accessible within the protein (Fig. 5B and 6). Cys-46 is located within the N-terminal $\mathrm{C} 2 \mathrm{H} 2$ zinc finger (ZF), and Cys-894 is found in the coiled coil domain of EEA1 [35]. It has been shown that the ZF domain binds to Rab5 switch I and II regions, influencing the active switch conformation of the latter protein [35]. Cysteine residues can form disulphide bonds that play structural function in protein folding [36]. Therefore, S-nitrosylation of Cys-894 in EEA1 may affect its dimerisation, a configuration that is thought to carry a tethering function [37]. It may be possible that this S-nitrosylation leads to the dimerisation of EEA1, which in turn recruits multiple Rab5 effectors (e.g. Rab5a, Rabex-5 and Rabaptin) and other endosomal proteins such as Syntaxin-13 and SNARE that regulates endosome fusion and trafficking [38]. Since EEA1 was found to be S-nitrosylated, we investigated whether other early endosome proteins are S-nitrosylated. The data showed that Rab5 was found to be S-nitrosylated (Fig. 5B). This S-nitrosylation might have occurred on Cys-212 (Fig. 7), a cysteine residue that can also be S-geranylgeranylated [39]. This may suggest that NOS might regulate the anchoring of Rab5 onto membranes. In addition to Rab5, the APPL1 adaptor protein, localised in some Rab5-positive endosomes were investigated for S-nitrosylation [40]. Our results showed the detection of S-nitrosylated APPL1 (Fig. 5B). Two cysteine residues, Cys-99 and Cys-603, were found to be putative targets for S-nitrosylation. Cys-66 is found in the Bin-Amphiphysin-Rvs (BAR) domain, while Cys-603 is located in the phosphotyrosine binding (PTB) domain [40]. However, these residues were found to be hardly ac- 
cessible since they were hidden within the protein (Fig. 8), suggesting that another post-translation modification or interaction with another protein in the endosome may be implicated in the change of APPL1 conformation, where the latter become more accessible for S-nitrosylation. Since the BAR domain of APPL1, interacts with Rab5 and in its responsible for endocytic trafficking [40].

In this study, we identified for the first time that NOS may act as positive regulators of cell migration and FA turnover through a process that may rely on early endosomes trafficking in MDA-MB-231 breast cancer cells. Given the limitations of this study, we will need to further investigate the role of NO on early endosomes trafficking. It will be essential to investigate whether the acute effect of NOS inhibitors affect the S-nitrosylation of EEA1 and APPL1. In addition, the effect of NO donors still needs to be established. It would be valuable to investigate whether NO donors reverse the effect of NOS inhibitors. Mutagenesis approaches which would introduce mutations on the dimerisation sites/Rab5 binding domain within EEA1, where the cysteine residues are located should enable prevent their $\mathrm{S}$-nitrosylation in other to further clarify the role of NO in the regulation of endosome trafficking. Similar approaches should be applied to other endosome proteins such as Rab5 and APPL1. The observations on cell migration and FA turnover need to be confirmed with protein knockdown using siRNA or shRNA.

\section{Conclusions}

Our work suggests that NO might be involved in the regulation of FA turnover, and this may rely on early endosomal trafficking. This study provides supporting evidence for the claim that NO plays a role in cell migration and FA dynamics, particularly in MDA-MB-231 breast cancer cells - suggesting that these findings may present some therapeutic importance for cancer research.

\section{Ethical approval}

The conducted research is not related to either human or animal use.

\section{Acknowledgments}

We thank the Saudi Arabia ministry of higher education and the University of Reading for providing the financial support and the facilities needed to carry out this study. This work was supported by Saudi Ministry of Higher Education.

\section{Corresponding author}

Bandar Fahad Alharbi, University of Hail, Department of clinical laboratory, College of Applied Medical Science, Hail, P.O. Box: 2240, Saudia Arabia, email: b.alharbi@uoh.edu.sa.

\section{Conflict of interest}

The authors declare they have no conflict of interest.

\section{References}

1. Thomsen LL, Miles DW, Happerfield L, Bobrow LG, Knowles RG, Moncada S. Nitric oxide synthase activity in human breast cancer. Br J Cancer. 1995;72(1):41-4; DOI: 10.1038/bjc.1995.274.
2. Hermann M, Flammer A, LüscherTF.Nitric Oxidein Hypertension.JClinHypertens. 2006;8(s12):17-29; DOI: 10.1111/j.1524-6175.2006.06032.x.

3. Cianchi F Cortesini C, Fantappiè O, Messerini L, Schiavone N, Vannacci A, Nistri S, Sardi I, Baroni G, Marzocca C, Perna F, Mazzanti R, Bechi $\mathrm{P}$, Masini E. Inducible nitric oxide synthase expression in human colorectal cancer: correlation with tumor angiogenesis. Am J Pathol 2003;162(3):793-801; DOI: 10.1016/S0002-9440(10)63876-X.

4. Okayama H, Saito M, Oue N, Weiss JM, Stauffer J, Takenoshita S, Wiltrout RH, Hussain SP, Harris CC. NOS2 enhances KRAS-induced lung carcinogenesis, inflammation and microRNA-21 expression. Int J Cancer. 2013;132(1):9-18; DOI: 10.1002/ijc.27644.

5. Arcos M, Gorelik G, Klecha A, Goren N, Cerquetti C, Cremaschi G. Inducible nitric oxide synthase-mediated proliferation of a T lymphoma cell line. Nitric Oxide. 2003;8:111-8; DOI: 10.1016/S1089-8603(02)00181-7.

6. Massi D, Franchi A, Sardi I, Magnelli L, Paglierani M, Borgognoni L, Reali $\mathrm{U}$, Santucci M. Inducible nitric oxide synthase expression in benign and malignant cutaneous melanocytic lesions. J Pathol. 2001;194:194-200; DOI: 10.1002/1096-9896(200106)194:2\%3c194::AID-PATH851\%3e3.0. CO;2-S.

7. Zhan R, Yang S, He W, Wang F, Tan J, Zhou J, Yang S, Yao Z, Wu J, Luo G. Nitric oxide enhances keratinocyte cell migration by regulating Rho GTPase via cGMP-PKG signalling. PLoS One. 2015;10(3):e0121551; DOI: 10.1371/journal.pone.0121551.

8. Schäffer MR, Tantry U, Gross SS, Wasserkrug HL, Barbul A. Nitric oxide regulates wound healing. J Surg Res. 1996;63(1):237-40; DOI: 10.1006/ jsre.1996.0254.

9. Rath G, Dessy C, Feron 0. Caveolae, caveolin and control of vascular tone: nitric oxide (NO) and endothelium derived hyperpolarizing factor (EDHF) regulation. J Physiol Pharmacol. 2009;60 Suppl 4:105-9.

10. Feron O, Balligand J-L. Caveolins and the regulation of endothelial nitric oxide synthase in the heart. Cardiovasc Res. 2006;69(4):788-97; DOI: 10.1016/j.cardiores.2005.12.014.

11. Shaul PW. Endothelial nitric oxide synthase, caveolae and the development of atherosclerosis. J Physiol. 2003;547(1):21-33; DOI: 10.1113/ jphysiol.2002.031534.

12. Wang G, Moniri N, Ozawa K, Stamler J, Daaka Y. Nitric oxide regulates endocytosis by S-nitrosylation of dynamin. Proc Natl Acad Sci U S A. 2006;103:1300; DOI: 10.1073/pnas.0508354103.

13. Foster MW, Hess DT, Stamler JS. Protein S-nitrosylation in health and disease: a current perspective. Trends Mol Med. 2009;15(9):391-404; DOI: 10.1016/j.molmed.2009.06.007.

14. Cao S, Yao J, McCabe TJ, Yao Q, Katusic ZS, Sessa WC, Shah V. Direct interaction between endothelial nitric-oxide synthase and dynamin-2: implications for nitric-oxide synthase function. Journal of Biological Chemistry. 2001;276(17):14249-56; DOI: 10.1074/jbc.M006258200.

15. Franco SJ, Rodgers MA, Perrin BJ, Han J, Bennin DA, Critchley DR, Huttenlocher A. Calpain-mediated proteolysis of talin regulates adhesion dynamics. Nat Cell Biol. 2004;6(10):977-83; DOI: 10.1038/ncb1175.

16. Cortesio CL, Boateng LR, Piazza TM, Bennin DA, Huttenlocher A. Calpain-mediated proteolysis of paxillin negatively regulates focal adhesion dynamics and cell migration. J Biol Chem. 2011;286(12):9998-10006; DOI: $10.1074 /$ jbc.M110.187294.

17. Youn J-Y, Wang T, Cai H. An ezrin/calpain/PI3K/AMPK/eNOSs1179 signaling cascade mediating VEGF-dependent endothelial nitric oxide production. Circ Res. 2009;104(1):50-9; DOI: 10.1161/ CIRCRESAHA.108.178467.

18. Broussard JA, Webb DJ, Kaverina I. Asymmetric focal adhesion disassembly in motile cells. Curr Opin Cell Biol. 2008;20(1):85-90; DOI: 10.1016/j.ceb.2007.10.009.

19. Alfahad D, Alharethi S, Alharbi B, Mawlood K, Dash P. PtdIns(4,5)P2 and PtdIns(3,4,5)P3 dynamics during focal adhesions assembly and disassembly in a cancer cell line. Turk J Biol. 2020;44(6):381-92; DOI: 10.3906/biy-2004-108.

20. Fang S, Sharma RV, Bhalla RC. Endothelial nitric oxide synthase gene transfer inhibits platelet-derived growth factor-BB stimulated focal adhesion kinase and paxillin phosphorylation in vascular smooth muscle cells. Biochem Biophys Res Commun. 1997;236(3):706-11; DOI: 10.1006/bbrc.1997.7035.

21. Yao J, Schoecklmann HO, Pröls F, Gauer S, Sterzel RB. Exogenous nitric oxide inhibits mesangial cell adhesion to extracellular matrix components. Kidney Int. 1998;53(3):598-608; DOI: 10.1046/j.1523-1755.1998.00793.x.

22. Rhoads JM, Chen W, Gookin J, Wu GY, Fu Q Blikslager AT, Rippe RA, Argenzio RA, Cance WG, Weaver EM, Romer LH. Arginine stimulates intestinal cell migration through a focal adhesion kinase dependent mechanism. Gut. 2004;53(4):514-22; DOI: 10.1136/gut.2003.027540.

23. McGuffin LJ, Atkins JD, Salehe BR, Shuid AN, Roche DB. IntFOLD: an integrated server for modelling protein structures and functions from amino acid sequences. Nucleic Acids Res. 2015;43(W1):W169-73; DOI: $10.1093 /$ nar/gkv236. 
24. McGuffin LJ, Shuid AN, Kempster R, Maghrabi AHA, Nealon JO, Salehe BR, Atkins JD, Roche DB. Accurate template-based modeling in CASP12 using the IntFOLD4-TS, ModFOLD6, and ReFOLD methods. Proteins. 2018;86(S1):335-44; DOI: 10.1002/prot.25360.

25. Xue Y, Liu Z, Gao X, Jin C, Wen L, Yao X, Ren J. GPS-SNO: computational prediction of protein S-nitrosylation sites with a modified GPS algorithm. PLoS One. 2010;5(6):e11290; DOI: 10.1371/journal.pone.0011290.

26. Chen X, Guan T, Li C, Shang H, Cui L, Li X-M, Kong J. SOD1 aggregation in astrocytes following ischemia/reperfusion injury: a role of NO-mediated S-nitrosylation of protein disulfide isomerase (PDI). J Neuroinflammation. 2012;9:237; DOI: 10.1186/1742-2094-9-237.

27. Jeon AR, Kim J-E. PDI knockdown inhibits seizure activity in acute seizure and chronic epilepsy rat models via S-nitrosylation-independent thiolation on NMDA receptor. Front Cell Neurosci. 2018;12; DOI: 10.3389/fncel.2018.00438.

28. Danijel P, Nikolina V, Ivan C, Zeljko BJ. Effect of nitric oxide donors S-nitroso-N-acetyl-DL-penicillamine, Spermine and PAPA NONOate on intracellular $\mathrm{pH}$ in cardiomyocytes. Clin Exp Pharmacol Physiol. 2012;39(9):772-8; DOI: 10.1111/j.1440-1681.2012.05734.x.

29. Bradley SA, Steinert JR. Characterisation and comparison of temporal release profiles of nitric oxide generating donors. J Neurosci Methods. 2015;245:116-24; DOI: 10.1016/j.jneumeth.2015.02.024

30. Pervin S, Singh R, Chaudhuri G. Nitric oxide-induced cytostasis and cell cycle arrest of a human breast cancer cell line (MDA-MB-231): potential role of cyclin D1. Proc Natl Acad Sci U S A. 2001;98(6):3583-8; DOI 10.1073/pnas.041603998.

31. Kang-Decker N, Cao S, Chatterjee S, Yao J, Egan LJ, Semela D, Mukhopadhyay D, Shah V. Nitric oxide promotes endothelial cell survival signaling through S-nitrosylation and activation of dynamin-2. J Cell Sci. 2007;120(3):492-501; DOI: 10.1242/jcs.03361.

32. Gu C, Chang J, Shchedrina VA, Pham VA, Hartwig JH, Suphamungmee W, Lehman W, Hyman BT, Bacskai BJ, Sever S. Regulation of dynamin oligomerization in cells: the role of dynamin-actin interactions and its GTPase activity. Traffic. 2014;15(8):819-38; DOI: 10.1111/tra.12178.

33. Ozawa K, Whalen EJ, Nelson CD, Mu Y, Hess DT, Lefkowitz RJ, Stamler JS. S-nitrosylation of $\beta$-arrestin regulates $\beta$-adrenergic receptor trafficking. Mol Cell. 2008;31(3):395-405; DOI: 10.1016/j.molcel.2008.05.024.

34. Callaghan J, Simonsen A, Gaullier JM, Toh BH, Stenmark H. The endosome fusion regulator early-endosomal autoantigen 1 (EEA1) is a dimer Biochem J. 1999;338(Pt 2):539-43.

35. Mishra A, Eathiraj S, Corvera S, Lambright DG. Structural basis for Rab GTPase recognition and endosome tethering by the $\mathrm{C} 2 \mathrm{H} 2$ zinc finger of Early Endosomal Autoantigen 1 (EEA1). Proc Natl Acad Sci U S A 2010;107(24):10866-71; DOI: 10.1073/pnas.1000843107.

36. Berndt C, Lillig $\mathrm{CH}$, Holmgren A. Thioredoxins and glutaredoxins as facilitators of protein folding. BBA-Mol Cell Res. 2008;1783(4):641-50; DOI: $10.1016 /$ j.bbamcr.2008.02.003.

37. Dumas JJ, Merithew E, Sudharshan E, Rajamani D, Hayes S, Lawe D, Corvera S, Lambright DG. Multivalent Endosome Targeting by Homodimeric EEA1. Mol Cell. 2001;8(5):947-58; DOI: 10.1016/ S1097-2765(01)00385-9.

38. McBride HM, Rybin V, Murphy C, Giner A, Teasdale R, Zerial M. Oligomeric Complexes Link Rab5 Effectors with NSF and Drive Membrane Fusion via Interactions between EEA1 and Syntaxin 13. Cell. 1999;98(3):37786; DOI: 10.1016/S0092-8674(00)81966-2.

39. Farnsworth CC, Seabra MC, Ericsson LH, Gelb MH, Glomset JA. Rab geranylgeranyl transferase catalyzes the geranylgeranylation of adjacent cysteines in the small GTPases Rab1A, Rab3A, and Rab5A. Proc Nat Acad Sci U S A. 1994;91(25):11963-7; DOI: 10.1073/pnas.91.25.11963.

40. Diggins NL, Webb DJ. APPL1 is a Multi-Functional Endosomal Signaling Adaptor Protein. Biochem Soc Trans. 2017;45(3):771-9; DOI: 10.1042/ BST20160191. 